\title{
Morpho-physiology of wheat genotypes under different sowing dates as affected by Helminthosporium leaf blight and leaf rust in Chiwan, Nepal
}

\author{
SP Neupane ${ }^{1}$, BR Ojha ${ }^{2}$, SK Ghimire ${ }^{2}$, SK. Sah ${ }^{2}$, SM Shrestha $^{2}$, and RR Puri ${ }^{1}$ \\ ${ }^{1}$ CIMMYT South Asia Regional Office, Kathmandu Nepal \\ ${ }^{2}$ Institute of Agriculture and Animal Science, Chitwan, Nepal
}

\begin{abstract}
An experiment was conducted at the Agronomy farm of the Institute of Agriculture and Animal Science (IAAS), Rampur, Nepal in 2008/09. The experiment was laid out in factorial design in spit plot arrangement consisting of date of sowing as main factor and wheat genotypes as sub factor. Wheat genotypes were sown in 22 November for normal sowing and 29 December for late sowing condition. These were assessed against Helminthosporium leaf blight and leaf rust severity in a naturally inoculated environment. Result showed that wheat genotypes differed significantly with respect to flag leaf area, flag leaf duration and plant height. Genotype BL-3064 showed the lower decline (624.9 to 615.1) in chlorophyll content whereas RR-21 showed highest decline (471.2 to 360.4) in chlorophyll content from normal to late sowing, possibly contributing to resistant to the disease. The AUDPC value revealed that genotypes BL-3625 and BL-3623 had increased level of resistance due to lower AUDPC value and higher flag leaf duration. The results of this study suggest that genotypes BL-3623, BL-3625, BL-3063 and BL-3064 could be the option in warm and humid regions of Terai condition so far as resistant to Helminthosporium leaf blight and leaf rust are concerned.
\end{abstract}

Key words : wheat, variability, AUSRC, AUDPC, AURPC

\section{Introduction}

The physiological traits have caught the attention of breeders due to limitations of conventional yield-based selections, particularly for stressed environments (Reynolds et al., 2001). Application of such traits in addition to other traits such as chlorophyll content (AUSRC) and disease resistance might be useful to select and develop high performing genotypes. In Nepal, HLB develops as a complex of spot blotch, caused by Cochliobolus sativus (Ito \& Kurib.) Drechsler ex Dastur [anamorph Bipolaris sorokiniana (Sacc.) Shoemaker], and tan spot, caused by P. tritici-repentis (Died.) Drechs. [anamorph Drechslera tritici-repentis (Died.) Shoe-maker].

Leaf rust is common in warm humid Terai and inner Terai regions of Nepal caused by Puccinia recondita f.sp. tritici. Leaf rust epidemics is appeared in the month of March and heavy epidemic occurred in mid March where RR-21 had up to 80s rust infection recorded in farmer's field, while it was less in Farmer's Field Trial (NWRP, 2006/07). 


\section{Materials and methods}

The study was conducted at the Agronomy Farm of IAAS, Rampur, Chitwan, Nepal under normal sowing (22 November) and late sowing (29 December) condition of 2008/09.There was no rainfall recorded during the growth period of the crop. The mean maximum and minimum temperatures were $27.850 \mathrm{C}$ and $11.940 \mathrm{C}$, respectively for the crop season. The mean relative humidity was 87.38 $\%$ for the crop season. The soil was of sandy loam texture, moderately acidic having $\mathrm{pH}$ of 5.3.

The research was laid out in split plot design with sowing time as main plot factor and wheat genotypes as sub plot factor. The research consisting of 15 wheat genotypes among them 3 were checks of yield (Gautam), Helminthosporium leaf blight (RR 21) and leaf rust (Nepal 297) respectively. The total area of the sub plot was $2 \mathrm{~m} \times 1.5 \mathrm{~m}$. The row spacing was maintained to 25 $\mathrm{cm}$ with continuous sowing in the row. Each plot consisted of 6 rows. The central 4 rows by excluding $25 \mathrm{~cm}$ on both ends were treated as net plot rows. Fertilizer was applied as recommended for the experimental site, with 100, 60, and $40 \mathrm{~kg}$ ha- 1 of $\mathrm{N}, \mathrm{P} 2 \mathrm{o} 5$, and $\mathrm{K} 2 \mathrm{o}$, respectively. Individual plots were sown at the standard seed rate of $120 \mathrm{~kg}$ ha- 1 . Three irrigations were applied, as required in Nepal low land environments. The flag leaf area was calculated by multiplying flag leaf length and width by 0.7 (Aggarwal and Sinha, 1987). Similarly, flag leaf duration was calculated by subtracting the number of days of more than $90 \%$ flag leaf senescence from booting stage. The plant height of ten randomly selected plants from each plot was measured from the base of the plant at soil surface to the tip of the panicle excluding the awns.

Self-Calibrating Minolta Chlorophyll Meter (SPAD-502) was used to measure the amount of total chlorophyll content in leaves after complete heading of the wheat plant. In each plot, flag leaves of ten randomly tagged main tillers were used for SPAD measurements. The three dates of observations were based on the same flag leaf of the plant. Three SPAD readings were taken on each flag leaf randomly from tip to base and average figure was recorded.

Area under SPAD value Retreat Curve (AUSRC) was calculated using the following formula-

AUSRC $=\sum_{i=1}^{n-1}\left[\left(\frac{S_{(i+1)}+S_{i}}{2}\right)\right]\left(T_{(i+1)}-T_{i}\right)$

Where,

$\mathrm{Si}=$ Chlorophyll content of flag leaves on the ith date

$\mathrm{Ti}=$ Days from sowing up to the date of chlorophyll measurements

$\mathrm{n}=$ number of dates on which chlorophyll measurements were done

The double digit disease scoring techniques as outlined by Saari and Prescott (1975) was employed to assess HLB. A total of four scores of HLB were recorded after the initiation of flag leaf at the interval of seven days. The first digit (D1) represents relative height of disease progress and 
measure in 0 to 9 scales. Similarly, the second digit (D2) represents the intensity of disease and also measure in 0 to 9 scales.

Percent disease severity was estimated for each score based on the following formula.

Severity $(\%)=(\mathrm{D} 1 / 9) \times(\mathrm{D} 2 / 9) \times 100$

Where,

$\mathrm{D} 1=$ Height of disease progress from the ground level to canopy

$\mathrm{D} 2=$ Intensity of disease progress on diseased leaf area

Severity of the four scores was used to calculate the area under disease progress curve (AUDPC) by using the following formula given by Das et al. (1992).

$\mathrm{AUDPC}=\sum_{i=1}^{n-1}\left[\left(\frac{X_{(i+1)}+X_{i}}{2}\right)\right]\left(T_{(i+1)}-T_{i}\right)$

Where,

$\mathrm{Xi}=$ Disease severity on the ith date

$\mathrm{Ti}=$ Days from sowing up to the date of disease score

$\mathrm{n}=$ number of dates on which disease was recorded

The leaf rust intensities in wheat as based upon severity (percentage of rust infection on plants) and field response (type of disease reaction) outlined by Loegering was used for disease scoring. Severity was recorded as percentage, according to the modified Cobb Scale. The recording process relies upon visual observations, and was common to use the following intervals. Trace, 5, $10,20,40,60,100$ percent infection.

Field response was recorded using the following letters.

$\mathrm{O} \quad$ No visible infection on plants

$\mathrm{R} \quad$ Resistant; visible chlorosis or necrosis, no uredia were present

MR Moderately Resistant; small uredia were present

M Intermediate; variable size uredia were present, some with chlorosis, necrosis or both

MS Moderately Susceptible; medium size uredia were present, some with chlorosis, necrosis, or both

S Susceptible; large uredia were present, generally with little or no chlorosis or no necrosis

The Area Under Rust Progress Curve (AURPC) was calculated by the same formula as used for AUDPC of Helminthosporium Leaf Blight given by Das et al. (1992). The Average Coefficient of Infection (A.C.I.) of leaf rust disease in wheat genotypes was calculated by following method developed by Peterson et al. (1948). The disease severity and host response data were often combined into a single value called coefficient of infection (C.I.).with the different ACI readings, 
the area under rust progress curve (AURPC) was calculated as measure of disease resistance. The data were subjected to analysis of variance using MSTAT software. Mean separation was done by Duncan's Multiple Range Test (DMRT).

\section{Results and discussion}

\section{Analysis of Morpho-physiology traits}

The results of morpho-physiology traits of different wheat genotypes under normal and late sown condition is shown (Table 1).

Table 1. Effect of date of sowing and genotypes on Morpho-physiology traits of wheat at Rampur, Nepal during 2008/09

\begin{tabular}{lcclll}
\hline Treatments & \multicolumn{5}{c}{ Morpho-physiology traits } \\
& DH & DM & FLA & FLD & PHT \\
\hline A. Date of sowing & & & & & \\
22nd November & 64 & $126 \mathrm{a}$ & 29.84 & $56 \mathrm{a}$ & $95.35 \mathrm{a}$ \\
29th December & 58 & $103 \mathrm{~b}$ & 27.64 & $43 \mathrm{~b}$ & $86.92 \mathrm{~b}$ \\
LSD(0.05) & $\mathrm{ns}$ & 2.830 & ns & 2.473 & 4.449 \\
SEM \pm & 1.579 & 0.4651 & 0.4097 & 0.4064 & 0.7312 \\
B. Genotypes & & & & & \\
BL2800 & 63 & 119 & $26.75 \mathrm{bcd}$ & $49 \mathrm{bcd}$ & $94.51 \mathrm{bcde}$ \\
BL2884 & 63 & 116 & $26.66 \mathrm{bcd}$ & $48 \mathrm{~cd}$ & $92.06 \mathrm{cdef}$ \\
BL3264 & 61 & 115 & $23.77 \mathrm{~d}$ & $48 \mathrm{~d}$ & $92.50 \mathrm{cdef}$ \\
BL3063 & 58 & 112 & $34.37 \mathrm{a}$ & $55 \mathrm{a}$ & $87.43 \mathrm{efgh}$ \\
BL3064 & 59 & 113 & $31.52 \mathrm{ab}$ & $54 \mathrm{abc}$ & \\
BL3235 & 64 & 113 & $27.49 \mathrm{bcd}$ & $46 \mathrm{de}$ & $101.4 \mathrm{ab}$ \\
BL3237 & 63 & 114 & $24.37 \mathrm{~cd}$ & $47 \mathrm{de}$ & $98.85 \mathrm{abc}$ \\
BL3400 & 62 & 115 & $23.51 \mathrm{~d}$ & $49 \mathrm{bcd}$ & $83.58 \mathrm{gh}$ \\
BL3623 & 62 & 113 & $36.67 \mathrm{a}$ & $54 \mathrm{ab}$ & $82.46 \mathrm{gh}$ \\
BL3625 & 62 & 114 & $35.00 \mathrm{a}$ & $56 \mathrm{a}$ & $81.40 \mathrm{~h}$ \\
BL2930 & 65 & 118 & $31.08 \mathrm{ab}$ & $49 \mathrm{bcd}$ & $104.9 \mathrm{a}$ \\
NL971 & 65 & 116 & $30.66 \mathrm{abc}$ & $51 \mathrm{abcd}$ & $96.93 \mathrm{bcd}$ \\
RR21(HLB Check) & 59 & 107 & $22.60 \mathrm{~d}$ & $42 \mathrm{e}$ & $86.51 \mathrm{efgh}$ \\
Nepal-297(LR Check) & 56 & 112 & $25.15 \mathrm{bcd}$ & $46 \mathrm{de}$ & $85.37 \mathrm{fgh}$ \\
Gautam(Yield Check) & 63 & 117 & $31.48 \mathrm{ab}$ & $52 \mathrm{abcd}$ & $90.09 \mathrm{defg}$ \\
LSD(0.05) & $\mathrm{ns}$ & $\mathrm{ns}$ & 5.71 & 5.15 & 7.11 \\
SEM \pm & 2.23 & 2.90 & 2.02 & 1.82 & 2.51 \\
CV\% & $8.89 \%$ & $6.21 \%$ & $17.19 \%$ & $9.01 \%$ & $6.75 \%$ \\
\hline
\end{tabular}


Means followed by the common letter(S) are not significantly different based on DMRT at $\mathrm{P}=0.05$. $\mathrm{DH}=$ Days to Heading (in days), DM=Days to Maturity (in days), FLA=Flag Leaf Area ( $\mathrm{cm} 2)$, $\mathrm{FLD}=$ Flag Leaf Duration (in days) and PHT $=$ Plant Height (in $\mathrm{cm}$ )

The non significant effect of date of sowing on flag leaf area might be due to the fact that under high temperature, organ production is accelerated without any increase in net photosynthesis so there is less daily assimilates to be allocated to each organ. In late sowing condition, temperature above $250 \mathrm{C}$ had decreased relative growth rate of wheat through their influence on leaf growth as well as net assimilation rate and there by the flag leaf area was found non- significant on sowing date. The wheat genotypes demonstrate significantly different response to FLD because they were evolved from different population and having the different genetic base. The chlorophyll content was significantly influenced by date of sowing as well as genotype was presented (Table 2). Mercado et al. (2002) reported that correlation exists between SPAD value and chlorophyll content. In our findings significantly lower AUSRC was reported in late sowing condition because late sown wheat faces the problem of high temperature and hot winds which accelerates the developmental stages, reduces the size of the organ produced, and low biomass production (Weigand and Cueller, 1982; Fischer 1985 and Bhatta, 1992) so chlorophyll content was less.

\section{Assessment of Helminthosporium leaf blight and leaf rust disease}

There was significant $(\mathrm{p} \leq 0.05)$ effect of date of sowing on AUDPC. AUDPC was higher in late sowing condition (1016.0) in comparison with normal sowing condition (880.1) (Table 2). Dubin and Bimb (1994) found a higher level of conidial dispersal and blight caused by D.tritici-repentis compared to C. sativus in February while C.sativus became predominant later in the season with temperature increase and wheat maturity. Our finding was in line with the previous finding of Singh et al. (1998b) studied the effect of seeding date on spot blotch development and reported that the coincidence of higher foliar blight ( $80 \%$ blight intensity) was caused by B. sorokiniana under late sown conditions (December 20 ) as compared to lower HLB intensity $(60 \%)$ under early seeding (November 30) in Utter Pradesh, India. Kandel (2003) reported that disease increased with delayed sowing was due to confounding effect and/or enhancing effect of heat stress on Helminthosporium leaf blight development.

There was highly significant $(\mathrm{p} \leq 0.01)$ effect of date of sowing on AURPC. AURPC as a measure of slow-rusting was higher in late sowing condition (32.55) in comparison with normal sowing condition (12.61) (Table 2). In late sowing condition, there was more conducive weather for the pathogens to cause infection and plant parts were more susceptible to disease. It might be the fact that late sowing wheat appears to be faced by warm vapors and high wind velocities which may result in the release of more spores that prevails at the late sowing condition. Losses due to leaf rust damage are normally below $10 \%$ but can at times be as severe as $30 \%$ under late sowing condition (Singh et al., 1988; Trench et al., 1992; Boshoff et al., 2002; Curtis et al., 2002; Singh et al., 2002). 
Table 2. Effects of date of sowing and genotypes on physiological and disease assessment traits of wheat at Rampur, Nepal during 2008/09

\begin{tabular}{|c|c|c|c|}
\hline \multirow[t]{2}{*}{ Treatment } & \multicolumn{3}{|c|}{ Physiological and disease assessment traits } \\
\hline & AUSRC & AUDPC & AURPC \\
\hline \multicolumn{4}{|l|}{ A. Date of Sowing } \\
\hline 22nd November & $586.1 \mathrm{a}$ & $880.1 \mathrm{~b}$ & $12.61 b(2.36)$ \\
\hline 29th December & $546.9 \mathrm{~b}$ & 1016.a & $32.55 \mathrm{a}(3.72)$ \\
\hline $\operatorname{LSD}(0.05)$ & 7.409 & 127.6 & 0.4943 \\
\hline $\mathrm{SEM} \pm$ & 1.218 & 20.98 & 0.08124 \\
\hline \multicolumn{4}{|l|}{ B. Genotypes } \\
\hline BL2800 & $565.0 \mathrm{bc}$ & $809.1 \mathrm{gh}$ & $0.25 \mathrm{e}(0.82)$ \\
\hline BL2884 & $570.9 b c$ & 1094.bc & $0.96 \mathrm{e}(1.20)$ \\
\hline BL3264 & $564.7 \mathrm{bc}$ & 940.9 def & $0.00 \mathrm{e}(0.71)$ \\
\hline BL3063 & $620.1 \mathrm{a}$ & $856.3 \mathrm{fgh}$ & $0.00 \mathrm{e}(0.71)$ \\
\hline BL3064 & $620.0 \mathrm{a}$ & $884.7 \mathrm{fg}$ & $0.00 \mathrm{e}(0.71)$ \\
\hline BL3235 & $562.2 \mathrm{bc}$ & 1009.bcde & $189.0 \mathrm{a}(13.43)$ \\
\hline BL3237 & $555.2 \mathrm{bc}$ & 1051.bcd & $56.23 b(7.09)$ \\
\hline BL3400 & $548.8 \mathrm{c}$ & $996.9 \mathrm{cde}$ & $5.99 \mathrm{~d}(2.36)$ \\
\hline BL3623 & $622.2 \mathrm{a}$ & $598.3 \mathrm{i}$ & $5.73 \mathrm{~d}(2.26)$ \\
\hline BL3625 & $617.0 \mathrm{a}$ & $593.3 \mathrm{i}$ & $0.00 \mathrm{e}(0.71)$ \\
\hline BL2930 & $577.6 \mathrm{~b}$ & 898.8efg & $49.23 \mathrm{~b}(6.87)$ \\
\hline NL971 & $573.9 \mathrm{bc}$ & $847.6 \mathrm{fgh}$ & $0.00 \mathrm{e}(0.71)$ \\
\hline RR21(HLB Check) & $415.8 \mathrm{e}$ & 1773.a & $5.99 \mathrm{~d}(2.36)$ \\
\hline Nepal-297(LR Check) & $501.9 \mathrm{~d}$ & 1116. b & $25.32 \mathrm{c}(4.94)$ \\
\hline Gautam (Yield Check) & $582.4 \mathrm{~b}$ & $754.8 \mathrm{~h}$ & $0.00 \mathrm{e}(0.71)$ \\
\hline $\operatorname{LSD}(0.05)$ & 24.10 & 102.1 & 0.78 \\
\hline $\mathrm{SEM} \pm$ & 8.506 & 36.05 & 0.28 \\
\hline $\mathrm{CV} \%$ & $3.68 \%$ & $9.31 \%$ & $22.32 \%$ \\
\hline
\end{tabular}

Means followed by the common letter (S) are not significantly different based on DMRT at $\mathrm{P}=0.05$. Values in the parenthesis are the transformed values. AUSRC $=$ Area Under SPAD Retreat Curve, AUDPC $=$ Area Under Disease Progress Curve, AURPC $=$ Area Under Rust Progress Curve.

\section{Acknowledgements}

We are immensely grateful to Directorate of Research (DOR) for providing research grant and also acknowledge to IAAS, Rampur, Chitwan for providing research field and timely completion of research work. 


\section{References}

Aggarwal, PK, and SK Sinha. 1987. Response of droughted wheat to mid-season water application. Recovery in leaf area and its effects on grain yield. Aust. J. Plant Physiol.14. 227-237.

Bhatta, MR. 1992. Variation in morpho-physiological characters of spring wheat Triticum aestivum L. evaluated under normal and late planting conditions. Thesis. Unpublished M.Sc. (Ag.). UPLB, Los Banos, Philippines. pp. 3-32.

Bhatta, MR. 1996. Present status of wheat breeding research in Nepal. Proceedings of National winter crops technology workshop, NARC, Bhairahawa. pp. 19-41.

Boshoff, WHP, ZA Pretorius, and BDVan Niekerk. 2002. Establishment, distribution and pathogenicity of Puccinia striiformis f.sp. tritici in South Africa. Plant Disease 86. 485492.

Curtis, BC, S Rajaram, and HG Macpherson (eds.). 2002. Bread wheat improvement and production No. 30. Food and Agriculture Organization of the United Nations, Rome, Italy. 554 p.

Das, MK, S Rajaram, CC Mundt, and WE, Kronstad.1992. Inheritance of slow rusting resistance to leaf rust in wheat. Crop Sci. 32. 1452-1456.

Dubin, HJ, B Arun, SN Begam, M Bhatta, R Dhari, LB Goel, AK Joshi, BM Khanna, PK Malaker, DR Pokhrel, MM Rahman,NK Saha, MA Shaheed, RC Sharma, AK Singh, RM Singh, RV Singh, M Vargas, and PC Verma. 1998. Results of the South Asia regional Helminthsporium leaf blight and yield experiments, 1993-94. In. E. Duveiller et al. (ed.). Helminthosporium blights of wheat. Spot blotch and tan spot. CIMMYT, Mexico City. pp. 182-187.

Mercado, D, ME Renard, E Duveiller, and H Maraite.2002. Recent leaf blight surveys in South Asia and characterization of Drechsleara tritici-repentis isolates. In. B. Ramussen, Tim L. Friesen, and Shaukat Ali (eds.). Proceedings of the Fourth International Wheat Tan Spot and Spot Blotch Workshop. July 21-24. Bemidji, Minnesota, USA. pp. 20-23.

NWRP. 2006/07. Annual report. National Wheat Research Program. Nepal Agriculture Research Council, Rampur, Chitwan, Nepal. pp. 7-11.

Peterson, RF, AB Campbell, and AE Hannah. 1948. A diagrammatic scale for rust intensity on leaves and stems of cereals. Can. J. Res. 26. 496-500.

Plant Physiol. 72. 297-302.

Reynolds MP, R.M. Trethowan, M Van Ginkel, and S Rajaram. 2001. Introduction. Application of Physiology in Wheat Breeding. In. M.P. Reynolds, J.I. Ortiz-Monasterio, A. McNab (eds). Application of Physiology in Wheat Breeding. CIMMYT, El Batán, DF, Mexico. pp. 2-10. 
Agronomy Journal of Nepal (Agron JN) Vol. 3. 2013

Saari, EE, and JM Prescott.1975. A scale for appraising the foliar intensity of wheat disease. Plant Dis. Rep. 59. 377-380.

Singh, RP, J. Huerta- Espino, and AP Roelfs. 2002. The wheat rusts. FAO Plant production and Protection Series 30. Bread Wheat. Improvement and Production. www.wheat/ FAO document Repository file / y4011 eog.htm. Retrieved on September 2002.

Singh, S, and A Salyavir. 1988. Evaluation of some Indian wheat or the attributes of slow rusting. Cereal Rust Powdery Mildew Bulletin. 16. 1-10.

Trench TN, DJ Wilkinson, and SP Esterhuysen. 1992. South African plant disease control handbook. Farmer Support Group. 553 p.

Weigand, CL, and JA Cueller. 1982. Duration of grain filling and kernel weight of wheat as affected by temperature. Crop. Sci. 21. 95-101. 